\title{
Examination of an absolute quantity of less than a hundred nanograms of proteins by amino acid analysis
}

\author{
Akiko Masuda • Naoshi Dohmae \\ Received: 30 January 2013 /Revised: 14 March 2013 / Accepted: 8 May 2013 /Published online: 30 May 2013 \\ (C) The Author(s) 2013. This article is published with open access at Springerlink.com
}

\begin{abstract}
We developed an ultra-sensitive method of amino acid analysis (AAA) for the absolute quantification of less than $100 \mathrm{ng}$ of proteins, in solution or on polyvinylidene difluoride (PVDF) membranes using an oxygen-free chamber for protein hydrolysis. We used a pre-label method with 6aminoquinolyl- $N$-hydroxysuccinimidyl carbamate for fluorescence detection, ion-pair chromatography with a reversedphase column, and an ultra-high-pressure high-performance liquid chromatography. We optimized both handling- and instrument-dependent factors for accurate quantification and showed that the least amount of proteins to quantify was determined by handling accuracy rather than instrumental limit for quantification which was $0.6 \mathrm{fmol} / \mathrm{amino}$ acid. As a new evaluation method for the handling accuracy, we adopted the protein identification by the obtained amino acid compositions by AAA and the Swiss-Prot database search without the restriction of species. As a result, the least amount of starting material for AAA was $16 \mathrm{ng}(0.24 \mathrm{pmol})$ for a solution of bovine serum albumin (BSA), $33 \mathrm{ng}(0.50 \mathrm{pmol})$ for BSA on a PVDF membrane, and $44 \mathrm{ng}(0.15$ pmol $)$ for thyroglobulin on a PVDF membrane. These results demonstrate that the ultra-sensitive AAA developed in this study is feasible for absolute quantification of biological significant protein.
\end{abstract}

Keywords Amino acid analysis · Protein quantification · Post-translational modifications - Absolute quantification . Protein hydrolysis $\cdot$ Proteomics

Published in the topical collection Amino Acid Analysis with guest editor Toshimasa Toyo'oka.

A. Masuda $\cdot$ N. Dohmae $(\triangle)$

Biomolecular Characterization Team, RIKEN,

2-1 Hirosawa, Wako,

Saitama 351-0198, Japan

e-mail: dohmae@riken.jp

A. Masuda

e-mail: aki@riken.jp

\section{Introduction}

Amino acid analysis (AAA) is classic but plays an important role as quantitative method in many biological, biomedical, and food analyses. AAA has been used for determination of absolute amount of free amino acids, peptides, or proteins not just for amino acid composition of proteins. The quantitative accuracy of AAA has recently been noted again and many applications have been reported [1-6]. In proteomics, mass spectrometry (MS) has become the most informative tool and has replaced AAA as a qualitative technique and also, most recently, as a quantitative method. Quantitative MS requires an accurate amount of peptide or protein calibrants; but gravimetric method based on the weighing of solid analyte is unsuitable for the purpose since peptides or proteins often contain unknown amount of bound salts and/or hydrated water. AAA has become an important quantitative method in obtaining absolute amount of these calibrants. Another benefit is that AAA is free of bias by the amino acid sequence of proteins since the proteins are completely hydrolyzed to the constituted amino acids before AAA. Therefore, AAA is applicable to the proteins that are not easy to be analyzed by sequence-dependent enzymatic proteolysis plus MS such as Lys- and Arg-rich histones (histones are inappropriate for application of MS with enzymatic proteolysis, because histones have many modifications on Lys and Arg residues that prevent a usage of typical enzyme such as trypsin cleaving the carboxyl side of Lys or Arg) or membrane proteins that possess large hydrophobic moiety. A previously unknown histone modification, hydroxylation of Lys, was recently identified and quantified by AAA [2]. In another example, the 3D structure of a membrane protein in solution predicted by molecular dynamics simulations was experimentally confirmed from quantification of intramolecular Cys-Cys bond formation by AAA [3] (distance between two Cys residues of the membrane protein can be estimated by quantification of 
intramolecular Cys-Cys disulfide bond formation since the disulfide bond is formed when the two residues are positioned enough close to each other).

In the early 1950s, AAA was originally accomplished by separation of amino acids with ion-exchange chromatography, labeling of the amino acids with ninhydrin, and detection of them by visible light absorbance [7, 8]. The sensitivity of the AAA with the ninhydrin detection is not sufficient for small amount of proteins. Therefore, many sensitive methods for detection of amino acids have been developed based on chemical modifications of amino acids for fluorometry [9-12] or MS [13-15] before amino acid separation by liquid chromatography (LC), i.e., pre-column derivatization. In the precolumn derivatization, the hydrophobicity of amino acids can be enhanced, facilitating their separation by reversed-phase chromatography, which prevents dilution of peaks and enhances the sensitivity of detection. These pre-column labeling methods provide femtomole to picomole sensitivity to AAA $[16,17]$. In this study, we quantified amino acids by a pre-column derivatization with 6-aminoquinolyl- $N$-hydroxysuccinimidyl carbamate (AQC) for fluorescence detection because of three reasons: the reagent react with all amino acids including the secondary amino acids, the derivatized amino acid are stable at room temperature, the derivatization reaction is linear with amount of amino acids, and the excess reagent does not disturb analysis [12].

Because of development of highly sensitive AAA, quantification of free amino acids can be readily achieved in subpicomole level, but obtaining accurate quantity of lowabundance proteins (less than $100 \mathrm{ng}$ ) after hydrolysis steps without or less contamination from environment is far more difficult [18, 19]. For accurate quantification of amino acids in protein samples, following three requirements must be satisfied.

First, protein samples must be purified and rendered homogeneous before hydrolysis, because the amino acids of contaminant proteins cannot be distinguished from those of the sample proteins. A favorite method for preparation of homogeneous protein samples is sodium dodecyl sulfate-polyacrylamide gel electrophoresis (SDSPAGE) because of its inherent high resolution and simplicity. Direct hydrolysis of proteins in polyacrylamide gels causes the liberation of large quantities of ammonia, which hinders the use of AAA because the excessive ammonia consumes the reagent used for the pre-column labeling of amino acids. To circumvent this issue, the separated proteins are electroblotted onto a polyvinylidene difluoride (PVDF) membrane and hydrolyzed on the membrane $[20,21]$. If the protein to quantify is not isolated from other proteins, the amount of the protein is unknown, whereas the total amount of protein mixture can be known by sum of multiplying amino acid amount by the each residual mass. Second, protein samples should be completely and quantitatively hydrolyzed to amino acids.
Many hydrolysis methods that utilize enzymes, strong bases, or strong acids are available, and the proper method depends on the aim of the analysis [22]. Hydrolysis using hydrochloric acid $(\mathrm{HCl})$ is currently universally applied to AAA, because $\mathrm{HCl}$ can cleave peptide bonds completely independent of the amino acid sequence and can easily be removed from hydrolysates by evaporation. Except for labile or inert amino acids under acidic conditions, most amino acids are obtained quantitatively from proteins by hydrolysis with $\mathrm{HCl}$ (see details in the "Experimental section"). Furthermore, we have developed an automated hydrolysis system using a solid acid catalyst, which yielded over $70 \%$ of the amino acids recovered after conventional hydrolysis of proteins with $\mathrm{HCl}$ [23]. Since the automated system cannot be used for hydrolyzing electroblotted samples, $\mathrm{HCl}$ was used in this study.

Third, contamination from environment during many complicated operations, SDS-PAGE, electroblotting, and hydrolysis, must be prevented or restricted. Among them, the hydrolysis of proteins is responsible for most analysis errors and a precise technique for handling small amounts of samples is necessary. Then a sufficient amount of protein, typically from one to several micrograms, has been used to overcome the contribution from potential contaminants for obtaining an accurate amino acid composition [17, 18]. In the previous work, highly sensitive AAA was reviewed, in which $0.5 \mu \mathrm{g}$ of bovine serum albumin (BSA) in solution was hydrolyzed and a part of them, 45 and $100 \mathrm{ng}$, was quantified [16]. Cohen et al. investigated in detail the relationship between hydrolyzed protein amount of sample solution and average errors in the composition dividing the categories according to the protein amount: trace analysis $(<100 \mathrm{ng})$, high sensitivity (100$500 \mathrm{ng}$ ), low intermediate (500-100 ng), high intermediate (1,000-2,000 ng), and high (>2,000 ng) [18]. They also showed similar investigation of dot-blotted protein solution to membranes collected from capillary electrophoresis [24]. In both cases, a steady increase in the average error as sample amount decreases was observed. At the high sensitivity range for proteins on the membrane and at the trace analysis range for protein solutions, the average errors in the composition reached around $20 \%[18,24]$. The reduction of the contamination from environment is most critical for accurate quantification of lowabundant proteins. The purpose of this study is that the method to obtain meaningful results from trace analysis (the amount hydrolyzed $<100 \mathrm{ng}$ of proteins both in solution and on membrane) is established by improving both handling- and equipment-dependent factors. The accuracy of AAA for less than $100 \mathrm{ng}$ of proteins was evaluated by the accuracy of amino acid composition and by assessing whether analyzed proteins were correctly identified from the obtained composition using the Swiss-Prot database. Only ten or a few tens of nanograms of BSA in solution or on a blotted membrane and thyroglobulin (TG) on a blotted membrane were correctly 
identified and quantified. These results demonstrate that AAA is a feasible method for biological significant proteins.

\section{Experimental section}

\section{Reagents}

BSA (A7638) and TG from bovine thyroid (T1001) were purchased from Sigma (St. Louis, MO). Sample solutions of BSA or TG were prepared on the basis of the dry weight of the proteins. $\mathrm{HCl}$, sodium tetraborate, Coomassie brilliant blue (CBB) R-250, and tetrabutylammonium bromide (TBA-Br) were purchased from Wako (Osaka, Japan). A type $\mathrm{H}$ amino acid standard containing 17 amino acids (2.5 mmol/1 each) was purchased from Pierce Chemical Co. (Rockford, IL), and LC/MS-grade acetonitrile (AN, A955-212) was purchased from Thermo Fisher Scientific Inc. (Waltham, MA). The phosphate buffer for chromatography was made from sodium dihydrogen phosphate monohydrate $\left(\mathrm{NaH}_{2} \mathrm{PO}_{4} \cdot \mathrm{H}_{2} \mathrm{O}, 106,346\right)$, and disodium hydrogen phosphate dihydrate $\left(\mathrm{Na}_{2} \mathrm{HPO}_{4} \cdot 2 \mathrm{H}_{2} \mathrm{O}, 106,580\right)$ was purchased from Merck KGaA (Darmstadt, Germany). 3cyclohexylamino-1-propanesulfonic acid (CAPS) was purchased from Nacalai Tesque, Inc. (Kyoto, Japan).

Amino acids were analyzed after pre-column derivatization with a fluorophore. The derivatization regent, AQC, was synthesized as described in previous reports [12,23], and purified to avoid unnecessary peaks that are due to side reaction with impurities of the synthesized AQC. The reagent is also commercially available from Waters (Waters corp., Milford, MA). For derivatization, the AQC powder was dissolved in dry acetonitrile to provide a $3 \mathrm{mg} / \mathrm{ml}$ solution (about $10 \mathrm{mM}$ ).

\section{Materials}

Small glass tubes $(6 \times 32 \mathrm{~mm}$, Crimp Top Vials, P/N: 03CVG, Chromacol, UK) for samples and glass vials $(27.75 \times$ $70 \mathrm{~mm}, \mathrm{P} / \mathrm{N}$ : 224832, Wheaton, $\mathrm{NJ}$ ) as hydrolysis vessels were pyrolyzed before use at $550{ }^{\circ} \mathrm{C}$ for $3 \mathrm{~h}$ to remove organic substances. Mininert valves (No. SC-24, P/N: 10130, Pierce, IL) were used for vacuum sealing of the glass vials before hydrolysis. The sample vials were heated by a heat block bath (Thermo Alumi bath ALB-121, Scinics Corporation, Tokyo, Japan) at hydrolysis.

Sample preparations

\section{One-dimensional SDS-PAGE and electroblotting}

One-dimensional SDS-PAGE was performed on commercial pre-cast gels $(8 \times 8 \times 0.1 \mathrm{~cm}, 12$ wells, $5-20 \%$ gradient; Bio Craft Co., Ltd., Tokyo, Japan). The BSA or TG solution was mixed with an equal volume of sample buffer (125 mM Tris-HCl, pH 6.8; 4 \% SDS; $20 \%$ glycerol; 0.2 M DTT; and $0.0125 \%$ bromophenol blue). Aliquots of the mixed solutions were loaded onto individual lanes of polyacrylamide gels and separated by electrophoresis at $10 \mathrm{~mA}$ for $3 \mathrm{~h}$ at room temperature.

Electroblotting onto a PVDF membrane (ProBlott, Applied Biosystems, Life Technologies Co., Carlsbad, CA) was carried out using a tank blotting procedure (KS8451, System Instruments Co. Ltd., Tokyo, Japan). Before electroblotting, the PVDF membrane was wetted in methanol and was equilibrated in CAPS transfer buffer $(10 \mathrm{mM}$ CAPS and $10 \%$ methanol at $\mathrm{pH} 11.0$ ) [25]. Blotting in CAPS transfer buffer is useful in reducing the level of Tris and glycine contamination from the polyacrylamide gel. The membrane was handled with gloves and forceps to avoid contamination from skin proteins. After electrophoresis, the gel and the membrane were sandwiched between gel blot papers (GB-003; Whatman, GE Healthcare) and were placed in the blotting cassette in an ice box. Electroblotting was carried out for $15 \mathrm{~min}$ at $0.5 \mathrm{~A}$ (constant current) in the CAPS transfer buffer. Then, the membrane was rinsed in Milli-Q water, stained with $0.2 \%$ CBB for $1 \mathrm{~min}$, and destained in the mixture of $50 \%$ methanol and $7.5 \%$ acetic acid at room temperature. The membrane was finally rinsed in Milli-Q water, air-dried in a glove box, and stored in doubled-over plastic bags in a refrigerator. In the glove box, the electroblotted bands of BSA or TG on PVDF membranes were excised over the inner plastic bag and rinsed with $50 \%$ acetonitrile in water before treatment with $20 \mathrm{mM} \mathrm{HCl}$. Each piece of the membrane was placed in the hydrolysis tube containing $50 \mathrm{pmol}$ of norvaline as an internal standard.

\section{Solution samples}

In the glove box, aliquot of BSA solution was placed in the hydrolysis tube containing $50 \mathrm{pmol}$ of norvaline as an internal standard.

Gas-phase hydrolysis

The hydrolysis tubes containing the sample on the PVDF membrane or in solution were set to a container with a cover and brought into an oxygen-free chamber for hydrolysis that we constructed. The chamber is under positive pressure of nitrogen to prevent oxidation of samples and to prevent contamination from the environment. After the sample container was brought in it, hydrolysis procedures were started when oxygen level in the chamber reached less than $0.1 \%$ detected by an oxygen monitor (JKO-O2LD II, JIKCO Ltd., Tokyo, Japan). The chamber is an appropriate glove box that includes stuff needed for hydrolysis: a vacuum line, a 
centrifugal concentrator, the heat block bath, and reagents for hydrolysis. The samples in the hydrolysis tubes were dried by the centrifugal concentrator with the vacuum line. The dried tubes were placed in the glass vial containing $200 \mu \mathrm{l}$ of constant-boiling $\mathrm{HCl}$ and a piece of phenol crystal. Then the vial was sealed under vacuum using the Mininert valve and heated at $110{ }^{\circ} \mathrm{C}$ for $20 \mathrm{~h}$ by the heat block bath $[16,23]$. After hydrolysis, the sample tubes were dried under vacuum.

\section{Derivatization of amino acids}

A standard solution containing a mixture of 50 pmol of standard amino acids and norvaline, and the hydrolysate of the BSA solution were derivatized by AQC as previously described $[16,23]$. The hydrolysate of BSA or TG from the blotted band was derivatized by adding the AQC solution directly into the hydrolysis tubes containing the PVDF membrane, as follows: The membrane was wetted with $5 \mu \mathrm{l}$ of acetonitrile, and then, $10 \mu \mathrm{l}$ of $20 \mathrm{mM} \mathrm{HCl}$ was added and vigorously stirred to extract the hydrolysate. Borate buffer $(25 \mu l$ and $0.2 \mathrm{M}$ at $\mathrm{pH} 8.8)$ was added, mixed, and finally $10 \mu \mathrm{l}$ of the AQC solution was added. The reaction mixtures were stirred immediately. After the mixtures were left to stand for $1 \mathrm{~min}$ at room temperature, they were heated at $55{ }^{\circ} \mathrm{C}$ for $10 \mathrm{~min}$. The derivatized solution was transferred to a new tube before chromatographic analysis to avoid adsorption of amino acids onto the membrane and piercing of the membrane by a needle of the autosampler. A tenth of the derivatized solution was analyzed by high-performance liquid chromatography (HPLC) as described in the next section.

Analytical procedures

\section{Chromatography}

AQC-amino acids of the hydrolysates and the standard solution of amino acids were separated by ion-pair chromatography using a reversed-phase column $[16,26]$. An Agilent HPLC system for ultra-high-pressure use (1200 SL series, pressure resistance $=600$ bar) equipped with binary pumps, a column oven, an autosampler, and a fluorescence detector (excitation at $250 \mathrm{~nm}$ and emission at $395 \mathrm{~nm}$ ) was used. In this system, fluorescence signal can be amplified by increasing the voltage applied to the photomultiplier of the fluorescence detector. We used middle-range voltage, except for obtaining the chromatogram of the 5-fmol amino acid standard solution, in which signals were amplified by approximately a factor of 10 against other measurements. The column used was an InertSustain C18HP column suitable for ultra-high pressure (pressure resistance $=500 \mathrm{bar}$ ), $3 \mu \mathrm{m}$, $3.0 \times 250 \mathrm{~mm}$ (GL Sciences Inc, Tokyo, Japan). Elution buffer A was $95 \%$ of $30 \mathrm{mM}$ phosphate buffer (pH 7.3) containing $5 \mathrm{mM}$ TBA-Br as the ion-pair reagent and $5 \%$ acetonitrile, whereas elution buffer B was $50 \%$ of $30 \mathrm{mM}$ phosphate buffer ( $\mathrm{pH} 7.3$ ) with $50 \%$ acetonitrile. The different two elution programs were used based on column condition: linear increases from $2 \% \mathrm{~B}$ at time 0 to $7.3 \%$ $\mathrm{B}$ at $2.7 \mathrm{~min}$, and then to $72.3 \% \mathrm{~B}$ at $26 \mathrm{~min}$ or to $72.3 \% \mathrm{~B}$ at $35.4 \mathrm{~min}$, followed by a wash with $99 \% \mathrm{~B}$ for $1.8 \mathrm{~min}$ and re-equilibration with $2 \% \mathrm{~B}$ for $12.4 \mathrm{~min}$. The column was kept at $42{ }^{\circ} \mathrm{C}$, the flow rate was $0.4 \mathrm{ml} / \mathrm{min}$, and the injected volume of the solution of AQC-derivatized amino acids was $5 \mu l$.

\section{Quantification}

Under the conditions of conventional acidic hydrolysis, Asn and Gln are completely hydrolyzed to Asp and Glu, respectively, and Trp, Cys, and cystine are partially destroyed [27]. We quantified Asp as the sum of Asp and Asn and Glu as the sum of Glu and Gln. For quantitative analysis, 50 pmol of the standard solution containing 17 amino acids (other than Trp, Asn, and Gln) was derivatized by the same procedure used with the hydrolyzed samples. A tenth of the total hydrolysate of the standard solution was injected onto the column. We evaluated the amounts of 17 amino acids in the samples by calculating the ratio of the peak height of an amino acid in the sample to that of the same amino acid in the standard. Total weight of amino acids was calculated by sum of multiplying the obtained amounts of amino acids by each residual mass. In all experiments for protein quantification, each sample was hydrolyzed and analyzed three times, and the standard deviation of the means was calculated as $\left(\sum(\text { experimental value }- \text { average value })^{2} / 2\right)^{1 / 2}$.

\section{Method validation}

We derivatized $150 \mathrm{pmol}$ of the amino acid standard, and the derivatized solution was diluted to make a dilution series of the standard. By plotting the quantified amount of AQC-Arg against the injected amount of AQC-Arg, we ascertained the linear range and the LOD (limit of detection) of the fluorescence detector. We defined the minimum amount that maintained the linear response as the LOQ (limit of quantification).

We validated the quantitative accuracy of AAA by protein identification using the amino acid compositions derived from the analyses and a search program of a protein database. For the Swiss-Prot database search, the ExPASy AACompIdent tool was used (http://web.expasy.org/ aacompident/) with constellation $2(\mathrm{Asp}+\mathrm{Asn}=\mathrm{Asx}, \mathrm{Gln}+$ $\mathrm{Glu}=\mathrm{Glx}$, and Cys and Trp are not considered) chosen without any limit of species, isoelectric point, or molecular weight of the proteins. Proteins, at amounts ranging from a 
few nanograms to several tens of nanograms, were quantified and validated. We defined the minimum quantity of protein that was identified correctly by the database search as the LOH (limit of handling).

\section{Results and discussion}

Chromatographic analysis of amino acids

Pre-column derivatization with fluorescent molecules enhances the hydrophobicity of amino acids and enables separation of amino acids by reversed-phase liquid chromatography (RPLC), resulting in faster analysis and higher sensitivity than that of conventional ion-exchange chromatography. In the case of RPLC, hydrophilic molecules elute earlier, and hydrophobic molecules are eluted later, with progressive elution at increasing ratios of organic solvents. In general, the fluorescence intensity of eluted compounds is stronger in hydrophobic circumstances. Therefore, in the case of fluorescence detection of eluted samples of RPLC, the fluorescence intensity of samples that are eluted later is stronger. The solvent effect leads to a different response factor for each amino acid, and the peak-areas of amino acids that are eluted earlier are almost one fifth smaller than the later one [12]. It is more difficult to quantify the amino acids with small response factors rather than those with large response factors especially in extremely small amount of samples. To circumvent this issue, we used an ion-pair reagent to enhance the hydrophobicity of the AQC-derivatives of hydrophilic amino acids and to reduce the solvent effect [26]. By application of the latest ultra-high-pressure LC, we were able to use a long column with small internal diameter and to improve theoretical plate-number and signal-to-noise ratio of chromatograms resulting in high sensitivity with excellent resolution. Figure 1 represents the typical chromatogram of $5 \mathrm{fmol}$ of the AQC-amino acid standard (after subtraction of the chromatogram of the blank/water).

\section{Quantification of small amounts of amino acids}

The sensitivity and linear response range of the detector need to be adequate enough to quantify small amounts of proteins. These requirements depend on the two kinds of limitations dependent on the performance of the fluorescence detector, LOD and LOQ. Usual photomultipliers, including those in fluorescence detectors, have a linear response range of two to four orders of sample quantities against the intensity of incident light. Because the response is not linear at both ends of the intensity plot, at the lowest and highest intensities of incident light, the amounts of amino acids cannot be quantified accurately even if the

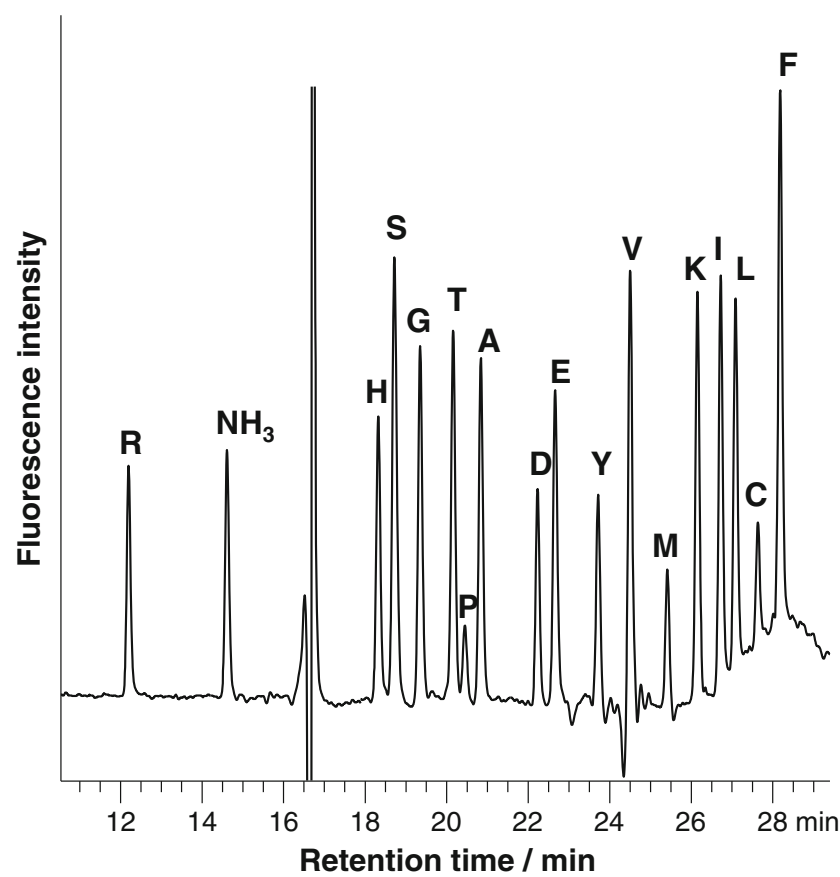

Fig. 1 Typical chromatogram of AQC-amino acid standards of $5 \mathrm{fmol}$ that subtracted a blank chromatogram of injection of water (gradient condition, 2-7.3-72.3\% B/0-2.7-26 min)

signals are detectable. We defined the sample limit at which the linear response is maintained as the LOQ and the lower limit at which the signal from the amino acids is still detectable as the LOD. We evaluated LOQ and LOD by measuring the detector response to a dilution series of AQCArg standards. The amounts of the AQC-Arg quantified are plotted against the injected amounts of AQC-Arg in Fig. 2. For our chromatographic condition and detection system, almost four-order linearity from 0.6 fmol to 5 pmol was observed, which means that the LOQ was $0.6 \mathrm{fmol}$. In contrast, the LOD was 50 amol, as shown in Fig. 2.

Recent developments in MS have enabled highly sensitive detection of free amino acids, and MS has also been used for AAA. There are basically two main methods to detect amino acids by MS. One of them is a non-labeling method, in which the amino acids are detected without derivatization. Miyano et al. [28] reported that the LOD of the non-labeling-based MS detection was 10-90 fmol. Another MS method is the pre-label method in which the amino acids are derivatized with reagents that are selectively cleaved during ionization and generate the same fragment for selective reaction monitoring (SRM). The pre-label method achieved an LOD of femtomoles to several tens of attomoles $[14,15]$. Since the advantages of SRM-MS are high selectivity and short analysis time, SRM-MS is suitable for metabolomics. To use these MS methods for quantification of amino acids, however, expensive equipment and stable isotope-labeled amino acids are needed, resulting in 


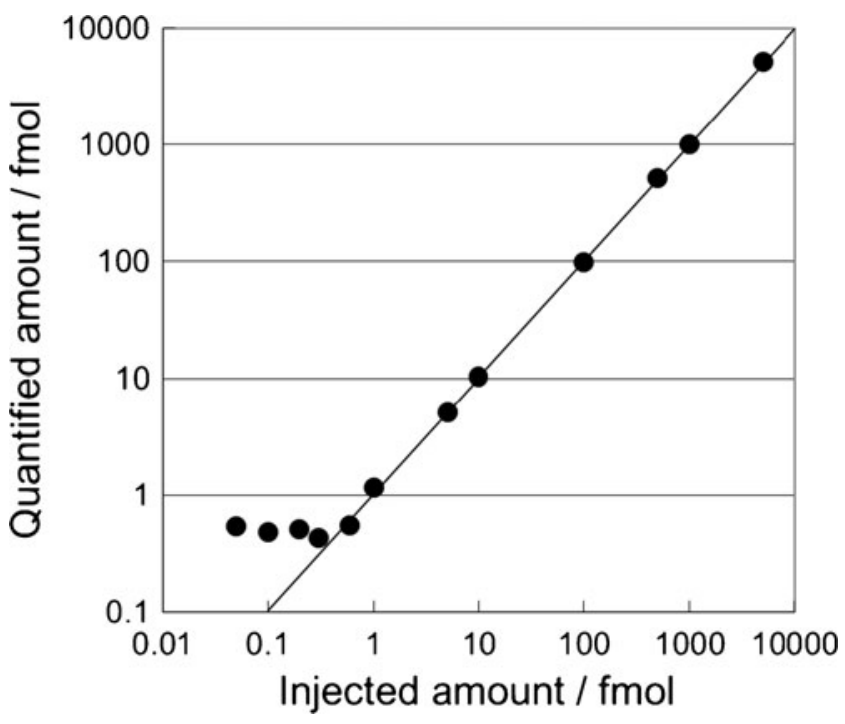

Fig. 2 Quantified amount of AQC-Arg was plotted against injected amount. Linearity of detector response confined the limit of quantification to $0.6 \mathrm{fmol}$, whereas limit of detection was $0.05 \mathrm{fmol}$

a high cost. Moreover, detection range for each amino acid is relatively narrow: two to four orders in concentration of amino acids [14].

The quantification of amino acids in proteins is more complicated than that of free amino acids because of the requirement for hydrolysis. The LOQ of amino acids in proteins depends on the quantitative recovery of amino acids via protein hydrolysis.

Actual limit for quantification of small amounts of proteins

For the quantification of small amounts of proteins, not only the LOQ but also the LOH dominates the quantitative results because one more process, hydrolysis, is needed before quantification of the released amino acids. Hydrolysis contains complicated operational steps that create a risk of contamination from the environment to the samples. Appropriate equipment, such as the oxygen-free chamber for hydrolysis, gloves, and forceps, as well as a proper technique for handling small amounts of samples, can prevent the contamination. Generally, a blank sample tube is simultaneously hydrolyzed with protein samples for background correction. Then the contributions from the contamination that are the background peaks of the blank sample are subtracted from the chromatogram of protein sample. However, the contamination to protein samples is not necessarily the same as that to the hydrolysis blank. Furthermore, there is so far no guideline how extent of contamination makes the quantification of proteins end in failure. As a new guideline, we defined the limit of handling accuracy, $\mathrm{LOH}$, and adopted the protein identification by the obtained amino acid compositions and the Swiss-Prot database for evaluation of the $\mathrm{LOH}$.

Table 1 Amino acid contents of BSA

\begin{tabular}{|c|c|c|c|c|c|}
\hline & $\begin{array}{l}\text { Theoretical } \\
\text { residue number }\end{array}$ & $\begin{array}{l}\text { BSA solution }(54 \mathrm{ng})^{\mathrm{a}} \\
\text { amount (pmol) }\end{array}$ & $\begin{array}{l}\text { BSA solution }(16 \mathrm{ng})^{\mathrm{a}} \\
\text { amount }(\mathrm{pmol})\end{array}$ & $\begin{array}{l}\text { BSA solution }(2.6 \mathrm{ng})^{\mathrm{a}} \\
\text { amount }(\mathrm{pmol})\end{array}$ & $\begin{array}{l}\text { blotted BSA (33 ng) } \\
\text { amount (pmol) }\end{array}$ \\
\hline $\operatorname{Arg}(\mathrm{R})$ & 23 & $19.2 \pm 0.47(24.5)^{\mathrm{b}}$ & $5.21 \pm 0.13(23.1)^{\mathrm{b}}$ & $0.855 \pm 0.05(21.0)^{\mathrm{b}}$ & $11.0 \pm 0.28(23.6)^{\mathrm{b}}$ \\
\hline His $(\mathrm{H})$ & 16 & $13.4 \pm 1.00(17.1)^{\mathrm{b}}$ & $3.79 \pm 0.12(16.8)^{\mathrm{b}}$ & $0.618 \pm 0.03(15.2)^{\mathrm{b}}$ & $6.96 \pm 0.10(14.9)^{\mathrm{b}}$ \\
\hline Ser $(S)$ & 28 & $22.7 \pm 0.45(29.0)^{\mathrm{b}}$ & $7.97 \pm 0.51(35.3)^{\mathrm{b}}$ & $2.56 \pm 0.01(63.0)^{\mathrm{b}}$ & $17.3 \pm 0.09(37.1)^{\mathrm{b}}$ \\
\hline Gly (G) & 16 & $14.9 \pm 0.23(19.0)^{\mathrm{b}}$ & $6.00 \pm 1.20(26.6)^{\mathrm{b}}$ & $1.94 \pm 0.03(47.7)^{\mathrm{b}}$ & $13.3 \pm 0.15(28.5)^{\mathrm{b}}$ \\
\hline $\operatorname{Thr}(\mathrm{T})$ & 33 & $27.9 \pm 0.68(35.6)^{\mathrm{b}}$ & $7.92 \pm 0.17(35.1)^{\mathrm{b}}$ & $1.35 \pm 0.06(33.2)^{\mathrm{b}}$ & $16.2 \pm 0.02(34.7)^{\mathrm{b}}$ \\
\hline Pro (P) & 28 & $22.3 \pm 0.60(28.5)^{\mathrm{b}}$ & $6.5 \pm 0.24(28.6)^{\mathrm{b}}$ & $1.02 \pm 0.04(25.1)^{\mathrm{b}}$ & $14.1 \pm 0.01(30.2)^{\mathrm{b}}$ \\
\hline Ala (A) & 47 & $38.6 \pm 0.87(49.3)^{\mathrm{b}}$ & $11.5 \pm 0.12(50.9)^{\mathrm{b}}$ & $1.96 \pm 0.08(48.2)^{\mathrm{b}}$ & $24.2 \pm 0.06(51.9)^{\mathrm{b}}$ \\
\hline Asp (D) & 55 & $44.4 \pm 1.40(56.7)^{\mathrm{b}}$ & $12.6 \pm 0.26(55.8)^{\mathrm{b}}$ & $2.27 \pm 0.11(55.9)^{\mathrm{b}}$ & $26.0 \pm 0.02(55.7)^{\mathrm{b}}$ \\
\hline Glu (E) & 79 & $71.0 \pm 1.90(90.7)^{\mathrm{b}}$ & $20.4 \pm 0.91(90.3)^{\mathrm{b}}$ & $3.61 \pm 0.17(88.8)^{\mathrm{b}}$ & $42.1 \pm 0.05(90.2)^{b}$ \\
\hline $\operatorname{Tyr}(Y)$ & 20 & $14.4 \pm 0.28(18.4)^{\mathrm{b}}$ & $4.06 \pm 0.25(18.0)^{\mathrm{b}}$ & $0.729 \pm 0.03(17.9)^{\mathrm{b}}$ & $9.72 \pm 0.12(20.8)^{\mathrm{b}}$ \\
\hline Val (V) & 36 & $28.3 \pm 0.80(36.2)^{b}$ & $8.05 \pm 0.23(35.7)^{\mathrm{b}}$ & $1.33 \pm 0.07(32.7)^{\mathrm{b}}$ & $17.2 \pm 0.07(36.9)^{\mathrm{b}}$ \\
\hline $\operatorname{Met}(\mathrm{M})$ & 4 & $3.33 \pm 0.13(4.3)^{\mathrm{b}}$ & $1.27 \pm 0.19(5.6)^{\mathrm{b}}$ & $0.205 \pm 0.00(5.0)^{\mathrm{b}}$ & $1.09 \pm 0.20(2.3)^{\mathrm{b}}$ \\
\hline Lys $(\mathrm{K})$ & 59 & $48.6 \pm 1.20(62.1)^{\mathrm{b}}$ & $13.4 \pm 0.22(59.3)^{\mathrm{b}}$ & $2.16 \pm 0.13(53.1)^{\mathrm{b}}$ & $27.3 \pm 0.11(58.5)^{\mathrm{b}}$ \\
\hline Ile (I) & 14 & $10.9 \pm 0.31(13.9)^{\mathrm{b}}$ & $3.54 \pm 0.18(15.7)^{\mathrm{b}}$ & $0.760 \pm 0.19(18.7)^{\mathrm{b}}$ & $6.96 \pm 0.10(14.9)^{\mathrm{b}}$ \\
\hline Leu (L) & 61 & $49.3 \pm 1.40(63.0)^{\mathrm{b}}$ & $14.0 \pm 0.32(62.0)^{\mathrm{b}}$ & $2.24 \pm 0.11(55.1)^{\mathrm{b}}$ & $30.2 \pm 0.03(64.7)^{\mathrm{b}}$ \\
\hline Phe $(F)$ & 27 & $21.7 \pm 0.56(27.7)^{b}$ & $6.18 \pm 0.14(27.4)^{b}$ & $1.03 \pm 0.05(25.3)^{\mathrm{b}}$ & $13.3 \pm 0.10(28.5)^{\mathrm{b}}$ \\
\hline Total amount (ng) & & 52 & 15 & 2.7 & 31 \\
\hline
\end{tabular}

${ }^{\mathrm{a}}$ These protein amounts were calculated from average of calculated protein amounts using obtained amounts of A, F, and L

${ }^{\mathrm{b}}$ The values in parentheses were calculated residue numbers from the obtained amounts of amino acids

${ }^{\mathrm{c}}$ The total amount was calculated by sum of multiplying the obtained amounts of amino acids by each residual mass 
We prepared three concentrations of BSA in solution, containing 2.6, 16, and $54 \mathrm{ng}$ of BSA, hydrolyzed the samples, and quantified the constituted amino acids. The amount of amino acids in picomoles and calculated total amount of amino acids in nanograms by the sum of multiplying the obtained amounts of amino acids by each residual mass are listed in Table 1. The calculated residue numbers from the amount of amino acids and molecular weight of BSA were also listed in Table 1. The residue number of the sample with $54 \mathrm{ng}$ of BSA matched the theoretical values, whereas a slight increase was observed in Ser and Gly values for the sample with $16 \mathrm{ng}$ of BSA. We assessed whether analyzed proteins were correctly identified by the Swiss-Prot protein database search without the restriction of species using these obtained composition and the ExPASY AACompIdent program. The results of the database search for 54 and 16 ng of BSA (shown in Table 2) indicated that both the samples were identified as BSA. However, the residue number of $2.6 \mathrm{ng}$ of BSA (listed in Table 1) deviated from the theoretical values, especially for Ser and Gly, and BSA was not hit until a rank of 10 . From the results, the LOH was $16 \mathrm{ng}$, or $240 \mathrm{fmol}$, of BSA in solution.

The LOQ of amino acids, $0.6 \mathrm{fmol}$, was one order lower than the obtained LOH. However, the increase of Ser and Gly prevented identification of the much smaller amount of protein such as $2.6 \mathrm{ng}$ for BSA solution. If the database search was performed using the calculated compositions of Ser and Gly derived from the theoretical residue numbers and the observed compositions of other amino acids, $2.6 \mathrm{ng}$ of BSA was successfully identified with a rank of 1 . Since the increase of Ser and Gly may be caused from a slight contamination from the environment, the contamination should be excluded or further minimized to accomplish the quantification of $1 \mathrm{ng}$ of protein, such as that achieved effectively by automation of sample preparation and/or sample hydrolysis [23].

Quantification of proteins electroblotted to PVDF membranes

The blotted protein bands are detected by staining with $\mathrm{CBB}$, with a detection limit around $50 \mathrm{ng}$ that sets the least value of $\mathrm{LOH}$. We cut off the protein bands containing $33 \mathrm{ng}$ of BSA or $44 \mathrm{ng}$ of TG, and the proteins were hydrolyzed on the membrane. The obtained amounts and calculated residue numbers of amino acids of the blotted BSA are listed in Table 1. In Fig. 3, the chromatogram of the hydrolysate of the blotted TG is shown. The injected amount of TG was one-tenth of the hydrolysate, i.e., $4.4 \mathrm{ng}$ (14.5 fmol). We
Table 2 The closest Swiss-Prot entries from the ExPASy AACompIdent program without the restriction of species, isoelectric point $(\mathrm{p} I)$, and molecular weight $(\mathrm{Mw})$

The program constellation 2 $($ Asp + Asn $=$ Asx, Gln + Glu $=$ Glx, and Cys and Trp are not considered) was used

\begin{tabular}{|c|c|c|c|c|c|}
\hline Rank & Score & Protein & $\mathrm{p} I$ & $\mathrm{Mw}$ & Description \\
\hline \multicolumn{6}{|c|}{ BSA solution (54 ng) } \\
\hline 1 & 2 & ALBU_BOVIN & 5.6 & 66,433 & Serum albumin \\
\hline 2 & 6 & ALBU_SHEEP & 5.58 & 66,328 & Serum albumin \\
\hline 3 & 11 & ALBU_RAT & 5.8 & 65,916 & Serum albumin \\
\hline 4 & 11 & ALBU_PIG & 5.84 & 66,798 & Serum albumin \\
\hline 5 & 11 & ALBU_MOUSE & 5.53 & 65,892 & Serum albumin \\
\hline \multicolumn{6}{|c|}{ BSA solution (16 ng) } \\
\hline 1 & 6 & ALBU_BOVIN & 5.6 & 66,433 & Serum albumin \\
\hline 2 & 11 & ALBU_SHEEP & 5.58 & 66,328 & Serum albumin \\
\hline 3 & 12 & ALBU_RAT & 5.8 & 65,916 & Serum albumin \\
\hline 4 & 13 & ALBU_MOUSE & 5.53 & 65,892 & Serum albumin \\
\hline 5 & 14 & ALBU_HORSE & 5.72 & 65,752 & Serum albumin \\
\hline \multicolumn{6}{|c|}{ Blotted BSA (33 ng) } \\
\hline 1 & 7 & ALBU_BOVIN & 5.6 & 66,433 & Serum albumin \\
\hline 2 & 12 & ALBU_SHEEP & 5.58 & 66,328 & Serum albumin \\
\hline 3 & 13 & ALBU_MOUSE & 5.53 & 65,892 & Serum albumin \\
\hline 4 & 14 & ALBU_RAT & 5.8 & 65,916 & Serum albumin \\
\hline 5 & 14 & ALBU_HORSE & 5.72 & 65,752 & Serum albumin \\
\hline \multicolumn{6}{|c|}{ Blotted TG (44 ng) } \\
\hline 1 & 5 & THYG_BOVIN & 5.5 & 301,219 & Thyroglobulin \\
\hline 2 & 11 & THYG_HUMAN & 5.42 & 302,728 & Thyroglobulin \\
\hline 3 & 15 & MNMC_IDILO & 5.54 & 67,069 & tRNA \\
\hline 4 & 16 & THYG_MOUSE & 5.32 & 302,414 & Thyroglobulin \\
\hline 5 & 17 & THYG_RAT & 5.04 & 30,252 & Thyroglobulin \\
\hline
\end{tabular}




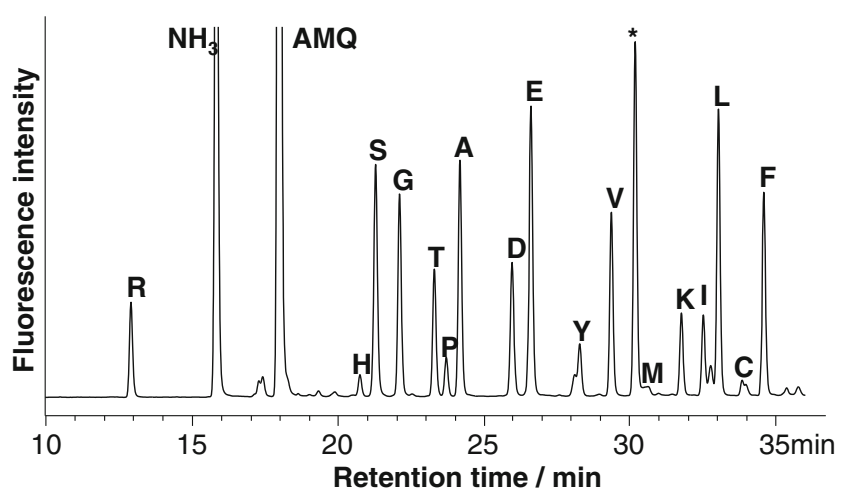

Fig. 3 Chromatogram of hydrolysate of blotted TG. A blotted band that contains $44 \mathrm{ng}$ (145 fmol) of TG was hydrolyzed and a tenth of them were injected. AMQ abbreviates 6 -aminoquinoline that is formed by hydrolysis of AQC. The asterisk-marked peak is an internal standard, norvaline (gradient condition, 2-7.3-72.3\% B/0-2.7-35.4 min)

verified the quantitative accuracy by performing the database search using the obtained amino acid composition. The composition matched the theoretical value, and the database search identified the protein bands as BSA or TG with a rank of 1 as shown in Table 2. The results mean the least value of $\mathrm{LOH}$ that is determined by the CBB detection limit was achieved in this study. The obtained LOH value for the electroblotted samples was the same extent as solution samples.

In a previous report, Murayama et al. [17] analyzed a part of the hydrolysate of a protein electroblotted onto PVDF, which was 2.4 fmol of multidrug-resistant protein 1 (MDR1, $160 \mathrm{kDa}$ ), and successfully identified it. However, they hydrolyzed an amount of MDR1 1,000 times larger than the injected amount to eliminate the influence of contamination. In other words, the LOH was 2.4 pmol in their case, although $2.4 \mathrm{fmol}$ of MDR1 was identified. In another report, Cohen et al. collected purified proteins by capillary electrophoresis onto PVDF membranes and hydrolyzed 100-700 ng of the collected proteins on the PVDF membranes. They reported that amino acid compositions of 100-700 ng of proteins were obtained with average errors 9.9-21.3\% [24]. They also pointed the average errors rose rapidly (30-60\%) for $60 \mathrm{ng}$ hydrolyzed samples. In our method, accurate AAA was accomplished for an order of small amount of proteins by accumulating small improvements in handling. For hydrolysate of $33 \mathrm{ng}$ of BSA or $44 \mathrm{ng}$ of TG on PVDF membrane, the average errors in the amino acid composition observed was $12 \%$. Since percent recovery of blotted BSA from amount on SDS-PAGE gel were reported as $35 \%$ [29], $94 \mathrm{ng}$ of BSA is needed as starting amount for SDS-PAGE.

\section{Conclusions}

We improved the sensitivity of AAA to the following specifications; an LOD of $50 \mathrm{amol}$, an LOQ of $0.6 \mathrm{fmol}$, and four orders of linearity. Critical manipulation before hydrolysis was done in the oxygen-free chamber under positive pressure of nitrogen to prevent oxidation of samples and to keep out dust.

In order to evaluate the $\mathrm{LOH}$ of proteins the protein identification was performed with the Swiss-Prot database search using the obtained compositions of amino acids and the ExPASy AACompIdent tool. As a result, hydrolysates from solution containing $16 \mathrm{ng}(240 \mathrm{fmol})$ of BSA, a PVDF membrane with $33 \mathrm{ng}$ (500 fmol) of electroblotted BSA, and a PVDF membrane with $44 \mathrm{ng}$ (145 fmol) of electroblotted TG were successfully identified. The LOH was less than one-tenth of that reported previously [17]. This method was practical for the quantification of proteins, at less than $100 \mathrm{ng}$ either in solution or on PVDF membranes. In the case of $2.6 \mathrm{ng}$ of BSA, the increase in Ser and Gly prevented identification of the protein. Thus a limitation of manual hydrolysis, namely the LOH, was likely a result of contamination with Ser and Gly from the environment. For further highly sensitive analysis, automation of sample preparation and/or sample hydrolysis will be effective in suppressing contamination and facilitating the quantification of $1 \mathrm{ng}$ of proteins.

Acknowledgments This work was supported in part by a Grant-inAid from the Ministry of Health, Labor and Welfare of Japan and the Chemical Genomics Research Project, RIKEN Advanced Science Institute (ASI), and by an Incentive Research Grant from RIKEN ASI.

Open Access This article is distributed under the terms of the Creative Commons Attribution License which permits any use, distribution, and reproduction in any medium, provided the original author(s) and the source are credited.

\section{References}

1. Matsumoto K, Nakayama H, Yoshimura M, Masuda A, Dohmae N, Matsumoto S, Tsujimoto M (2012) RNA Biol 9:610-623

2. Unoki M, Masuda A, Dohmae N, Arita K, Yoshimatsu M, Iwai Y, Fukui Y, Ueda K, Hamamoto R, Shirakawa M, Sasaki H, Nakamura Y (2013) J Biol Chem 288:6053-6062

3. Tsukazaki T, Mori H, Fukai S, Ishitani R, Mori T, Dohmae N, Perederina A, Sugita Y, Vassylyev DG, Ito K, Nureki O (2008) Nature 455:988-991

4. Kaspar H, Dettmer K, Gronwald W, Oefner PJ (2009) Anal Bioanal Chem 393:445-452

5. Steven L, Cohen M (2005) In: Molnár-Perl I (ed) Quantitation of amino acids and amines by chromatography (Journal of chromatography library, Vol.70). Elsevier, Amsterdam

6. Wilkins MR, Yan JX, Gooley AA (1999) Methods Mol Biol 112:445-460

7. Moore S, Stein WH (1951) J Biol Chem 192:663-681

8. Moore S, Stein WH (1954) J Biol Chem 211:893-906

9. Watanabe Y, Imai K (1981) Anal Biochem 116:471-472

10. Einarsson S, Josefsson B, Lagerkvist S (1983) J Chromatogr A 282:609-618

11. Lindroth P, Mopper K (1979) Anal Chem 51:1667-1674

12. Cohen SA, Michaud DP (1993) Anal Biochem 211:279-287

13. Kaspar H, Dettmer K, Chan Q, Daniels S, Nimkar S, Daviglus ML, Stamler J, Elliott P, Oefner PJ (2009) J Chromatogr B Analyt Technol Biomed Life Sci 877:1838-1846 
14. Shimbo K, Yahashi A, Hirayama K, Nakazawa M, Miyano H (2009) Anal Chem 81:5172-5179

15. Armenta JM, Cortes DF, Pisciotta JM, Shuman JL, Blakeslee K, Rasoloson D, Ogunbiyi O, Sullivan DJ Jr, Shulaev V (2010) Anal Chem 82:548-558

16. Masuda A, Dohmae N (2011) Biosci Trends 5:231-238

17. Shindo N, Fujimura T, Nojima-Kazuno S, Mineki R, Furusawa S, Sasaki K, Murayama K (1998) Anal Biochem 264:251-258

18. Cohen S A, De Antonis K, Michaud D P (1993) In: Angeletti R H (ed) Techniques in protein chemistry IV. Academic, San Diego

19. Bidlingmeyer BA, Tarvin TL, Cohen SA (1987) In: Walsh K A (ed) Methods in protein sequence analysis. Humana Press, Clifton, pp. 229-245

20. Hunziker P, Andersen TT, Bao Y, Cohen SA, Denslow ND, Hulmes JD, Mahrenholz AM, Mann K, Schegg KM, West KA, Crabb JW (1999) J Biomol Tech 10:129-136
21. Tous GI, Fausnaugh JL, Akinyosoye O, Lackland H, Winter-Cash P, Vitorica FJ, Stein S (1989) Anal Biochem 179:50-55

22. Kawahara-Kobayashi A, Masuda A, Araiso Y, Sakai Y, Kohda A, Uchiyama M, Asami S, Matsuda T, Ishitani R, Dohmae N, Yokoyama S, Kigawa T, Nureki O, Kiga D (2012) Nucleic Acids Res 40:10576-10584

23. Masuda A, Dohmae N (2010) Anal Chem 82:8939-8945

24. Cohen SA, Warren WJ (1994) In: Crabb JW (ed) Techniques in protein chemistry V. Academic, San Diego

25. Matsudaira P (1987) J Biol Chem 262:10035-10038

26. Shindo N, Nojima S, Fujimura T, Taka H, Mineki R, Murayama K (1997) Anal Biochem 249:79-82

27. Fountoulakis M, Lahm HW (1998) J Chromatogr A 826:109-134

28. Yoshida H, Mizukoshi T, Hirayama K, Miyano H (2007) J Agric Food Chem 55:551-560

29. Wong S, Padua A, Henzel WJ (1992) In: Angeletti RH (ed) Techniques in protein chemistry III. Academic, San Diego 